\title{
Estabilização química do solo com adição de sílica ativa e cimento, para utilização em camadas de pavimentação rodoviária
}

De acordo com a Confederação Nacional do Transporte (CNT), em 2018, cerca de $60 \%$ da produção brasileira foi escoada pelo modo de transporte rodoviário. Para proporcionar qualidade ao transporte, essas rodovias precisam atender a requisitos mínimos de resistência e drenabilidade, que iram proporcionar maior segurança e conforto ao usuário. Entretanto, nem sempre o solo local possui características geotécnicas mínimas que atendam aos requisitos de projeto. Para Machado et al. (2003), a carência de solos que possuem características exigidas pelos órgãos rodoviários, torna-se um empecilho para o setor de transportes no Brasil. Para resolver a problemática da carência, existem algumas alternativas, entre elas: mudança das características da obra para se adequar ao solo, mudança do solo, ou estabilização do solo local. No que se refere a essa última alternativa, ela consiste no melhoramento do solo através da adição de materiais como cimento, cal, sílica, entre outros. O presente trabalho apresenta o uso de sílica em comparação com o uso de cimento, para a estabilização de um solo de baixa qualidade, com a porcentagem de $15 \%$ de sílica ativa, bem como para o cimento, visto que se trata de um estudo comparativo. As características analisadas que para determinar o melhoramento são referentes à granulometria, plasticidade, massa específica, umidade ótima, além de CBR para determinação da resistência, juntamente com a expansão. Os resultados mostram que o uso da sílica contribui significativamente para a estabilização, mesmo que em menores porcentagens quando comparado ao uso do cimento. Entretanto, essa é uma alternativa que pode ser analisada de acordo com a viabilidade da utilização para as particularidades da obra a que for submetida.

Palavras-chave: Estabilização Geotécnica; Pavimentação Asfáltica; Sílica Ativa; Propriedades Geotécnicas.

\section{Chemical stabilization of soil with addition of active silica and cement for use in road pavement layers}

According to the National Transport Confederation (CNT), in 2018, about $60 \%$ of Brazilian production was disposed of by road transportation. To provide quality transportation, these highways must meet minimum strength and drainage requirements that will provide greater safety and comfort to the user. However, local soil does not always have minimal geotechnical characteristics that meet design requirements. For Machado et al. (2003), the lack of soils that have characteristics required by road agencies, becomes a hindrance to the transportation sector in Brazil. To solve the problem of lack, there are some alternatives, among them: change of the characteristics of the work to suit the soil, soil change, or local soil stabilization. About this last alternative, it consists of soil improvement through the addition of materials such as cement, lime, silica, among others. The present work presents the use of silica in comparison with the use of cement, for the stabilization of a low-quality soil with $15 \%$ of active silica, as well as for cement, since it is a comparative study. The characteristics analyzed that determine the improvement refer to the granulometry, plasticity, specific mass, optimum humidity, besides CBR to determine the resistance, along with the expansion. The results show that the use of silica contributes significantly to the stabilization, even in smaller percentages when compared to the use of cement. However, this is an alternative that can be analyzed according to the feasibility of use for the particularities of the work to which it is submitted.

Keywords: Geotechnical stabilization; Asphalt paving; Active Silica; Geotechnical properties

Topic: Engenharia Civil

Reviewed anonymously in the process of blind peer
Received: 07/01/2019

Approved: 09/03/2019
Lorhayne Well de Souza Almeida

Instituto Tocantinense Presidente Antônio Carlos Porto, Brasil http://lattes.cnpq.br/7735244603848869

lorhaynewellsa@gmail.com

Lucas Henrique Pereira de Souza

Centro Universitário Luterano de Palmas, Brasil

http://lattes.cnpq.br/2345879179574155

souzalucas0411@gmail.com

Willian Mateus de Souza Almeida

Universidade Federal do Tocantins, Brasil

http://lattes.cnpq.br/1286569200406852

willianmateus 13@hotmail.com

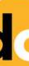

DOI: 10.6008/CBPC2318-3055.2019.001.0002
Flávio Vieira da Silva Júnior

Instituto Tocantinense Presidente Antônio Carlos Porto, Brasil http://lattes.cnpq.br/2211436659738090

flaviovisiju@gmail.com

Referencing this:

ALMEIDA, L. W. AS.; SOUZA, L. H. P.; ALMEIDA, W. M. S.; SILVA JÚNIOR, F. V.. Estabilização química do solo com adição de sílica ativa e cimento, para utilização em camadas de pavimentação rodoviária. Engineering Sciences, v.7, n.1, p.11-21, 2019. DOI: http://doi.org/10.6008/CBPC2318-3055.2019.001.0002 


\section{INTRODUÇÃO}

Em obras de engenharia, é ideal que se utilize o solo natural que existe no local da obra; isso porque torna a obra mais econômica, visto que não há gastos com a compra de solo que envolve o transporte, que para algumas regiões, as distâncias são grandes, e esses gastos costumam inviabilizar o projeto. Entretanto, o solo é um material complexo e nem sempre atende as necessidades da obra, principalmente no quesito de resistência. Para isso, torna-se necessário optar por alternativas viáveis, seja mudar o projeto para ser utilizado naquele determinado solo, seja a substituição do solo, ou seja, pela correção do solo, chamado de estabilização.

Obras como pavimentação necessitam de grandes quantidades de solos resistentes. No Brasil, cerca de $60 \%$ dos transportes são feitos através de rodovias, e para proporcionar qualidade ao transporte, as rodovias necessitam ser pavimentadas. Desse modo, a pavimentação é muito importante para o desenvolvimento do país, e devido a extensão do Brasil e a diversidade de solos encontrados, nem sempre os solos locais atendem as necessidades mínimas para pavimentar, nesse caso é necessário utilizar solo de outros locais ou fazer a estabilização.

A carência de solos que possuem características geotécnicas necessárias e suficientes, de acordo com os órgãos rodoviários que regulamentam a construção de estradas, torna-se uma grande dificuldade para o setor de transportes no Brasil, isso porque as maiores cargas e maiores volumes de cargas são transportados frequentemente a distâncias cada vez maiores e com a presença de problemáticas, dessa forma é exigido que as estradas, sejam elas pavimentadas ou vicinais, sejam transitáveis em qualquer época do ano. (MACHADO et al., 2003)

A estabilização de solo para rodovias consiste no melhoramento das características do solo através de alguma adição. Para Sartori (2015), alguns métodos de estabilização em rodovias utilizados no país são: uso de cimento e uso de cal ao solo. Esses dois materiais melhoram as características mecânicas do solo, como a resistência, a plasticidade e a permeabilidade. Dependendo do custo com o transporte de um solo melhor, pode ser mais viável fazer o uso desses materiais para estabilizar o solo local.

Sendo o cimento um material muito utilizado em estabilizações, devido a presença da pozolana em sua composição, esta pesquisa propõe o uso de sílica ativa, devido a mesma ser uma pozolana. Existem muitos estudos para estabilização de solo com a adição de sílica. Entretanto, esta é misturada a outros materiais, como a cal. Nesse sentido, para um embasamento teórico, destacam-se os trabalhos de Alcântara (2017), Klamt (2012) e Fernandes (2014).

O uso de sílica como aditivo auxiliar à cal hidratada, promoveu melhoras significativas nos trabalhos dos referidos autores. Constata-se melhoras na plasticidade, aumento da umidade ótima, diminuição da massa específica aparente seca, além do aumento da resistência mecânica do solo. Dessa forma, é perceptível que a sílica contribui substancialmente para a estabilização dos solos, inclusive para a pavimentação. 
O uso de cimento para a estabilização do solo é uma técnica muito difundida, onde se prevê ótimos resultados. Dessa forma, propõe-se a utilização da sílica em comparação com o uso do cimento nas mesmas proporções, de modo que atinja as características necessárias para ser utilizado em camadas de pavimentação rodoviária.

\section{METODOLOGIA}

\section{Procedimentos relacionados ao solo}

A metodologia do presente trabalho constitui numa subdivisão relativa à coleta, preparação e procedimentos direcionados solo, e aos procedimentos laboratoriais para caracterizar e ensaiar as misturas de solo com sílica ativa e solo com cimento. O solo utilizado foi coletado no setor Imperial, na cidade de Porto Nacional (TO), localizado em $10^{\circ} 43^{\prime} 32.2^{\prime \prime} \mathrm{S} 48^{\circ} 24^{\prime} 06.1^{\prime \prime} \mathrm{W}$, conforme a figura 1, nos entornos da pavimentação das ruas do setor. Escolhido devido ser o material descartado das camadas de pavimentação e, portanto, a princípio apresentar baixa resistência.

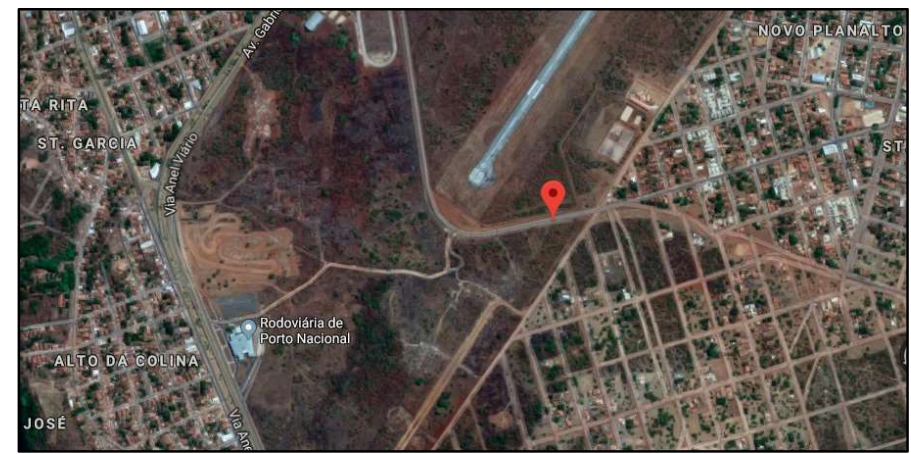

Figura 1: Local de coleta do solo.

Após a coleta, o solo foi destorroado, peneirado, espalhado e exposto para secagem ao ar, de modo que chegasse ao equilíbrio higroscópio com o meio. A partir da preparação, ele foi acondicionado para que pudesse ser utilizado nos ensaios laboratoriais, a partir dos laboratórios de solos e práticas do ITPAC Porto. No que se refere aos ensaios realizados no solo, foram feitos os seguintes ensaios: identificação tátil visual, sedimentação, análise granulométrica, determinação da massa específica dos sólidos, determinação dos limites de liquidez e de plasticidade, além do ensaio de compactação na energia proctor normal e posteriormente o ensaio de CBR e expansão. Cada ensaio foi realizado de acordo com as recomendações da Associação Brasileira de Normas Técnicas (ABNT).

\section{Procedimentos relacionados a mistura solo-sílica ativa}

Para os procedimentos adotados para a realização dos ensaios de solo com sílica, foram utilizados os percentuais adotados por Klamt (2012) e Fernandes (2014), que apresentaram bons resultados em seus trabalhos. Inicialmente, o solo natural já foi preparado para ensaios laboratoriais e, portanto, destinou-se uma parte para ser misturada com $15 \%$ de sílica. 
Após a mistura de $85 \%$ de solo com adição de $15 \%$ de sílica, em peso, como exemplificam as figuras 2 e 3 , esse material foi ensaiado da mesma forma que o solo natural, onde foram feitos os mesmos tipos de ensaios, de acordo com as normas pertinentes ao solo, sendo: sedimentação, análise granulométrica, determinação da massa específica dos sólidos, determinação dos limites de liquidez e de plasticidade, compactação na energia proctor normal, CBR e expansão.

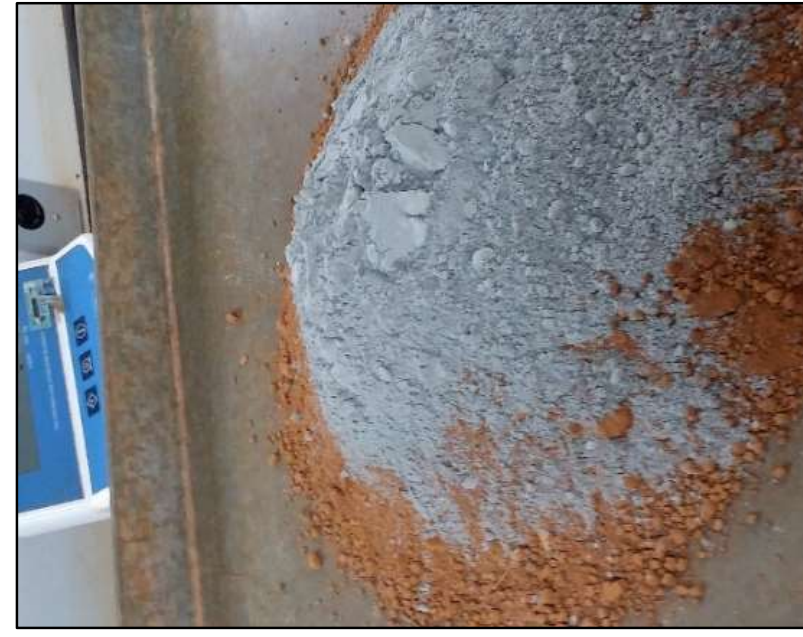

Figura 2: Mistura inicial de solo e sílica para o ensaio de compactação.

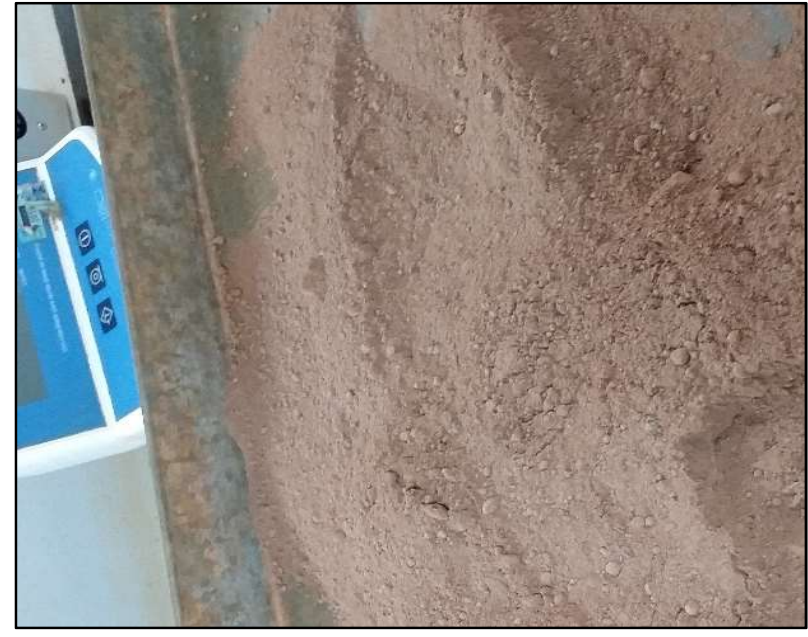

Figura 3: Mistura final de solo e sílica para o ensaio de compactação.

\section{Procedimentos relacionados a mistura solo-cimento}

Por se tratar de um estudo comparativo entre as misturas solo-sílica e solo-cimento para estabilização do solo, o mesmo método adotado para a sílica, foi adotado para o cimento. $\mathrm{O}$ cimento utilizado foi o Portland CP-32 II-F, e o material em questão foi misturado ao solo, considerando, também, $15 \%$ do peso total do material, conforme demonstra a figura 4.

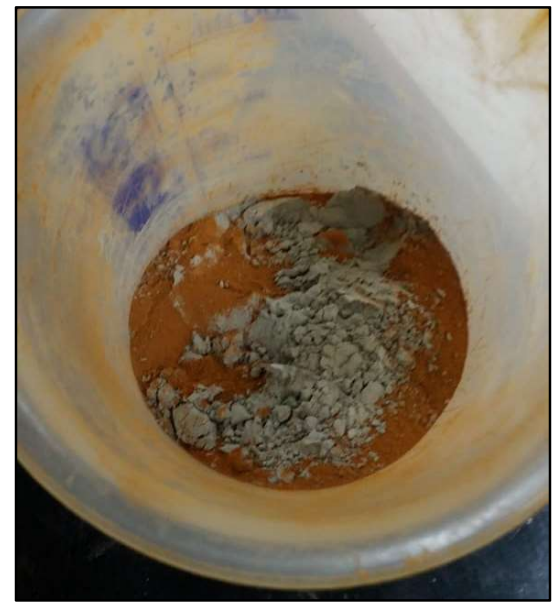

Figura 4: Mistura de solo e cimento para os ensaios de limite de plasticidade e liquidez.

Os ensaios adotados também foram os mesmos: sedimentação, análise granulométrica, determinação da massa específica dos sólidos, determinação dos limites de liquidez e de plasticidade, compactação na energia proctor normal, CBR e expansão. Os procedimentos adotados para os ensaios de CBR e expansão foram iguais para o solo natural e a mistura solo-sílica ativa com adição de $15 \%$ de sílica ativa em peso. 


\section{RESULTADOS E DISCUSSÃO}

Através do ensaio de identificação tátil visual, verificou-se que o solo estudado possui muitos grãos, sendo identificado inicialmente como um solo arenoso e, portanto, todos os ensaios foram feitos de acordo com as especificações das normas pertinentes para esse tipo de solo. A partir do ensaio de granulometria do solo, feito após o ensaio de sedimentação, foi obtido a seguinte curva de distribuição granulométrica, conforme a figura 5.

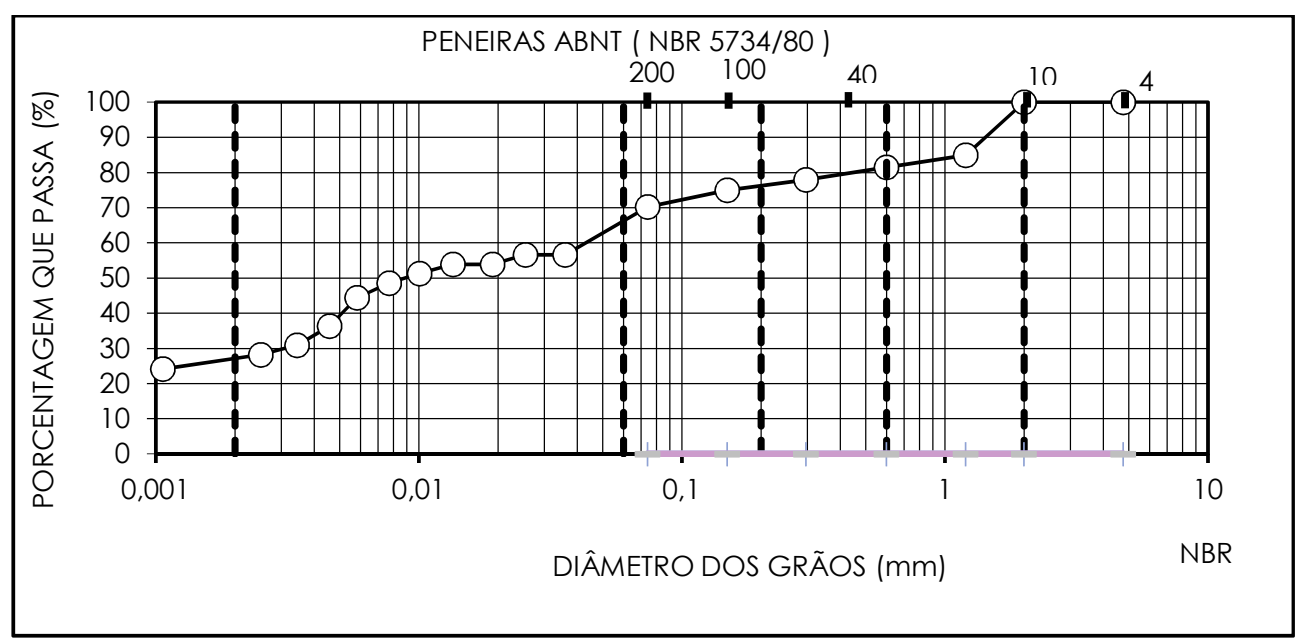

Figura 2: Gráfico de curva de distribuição granulométrica do solo natural.

A partir da curva apresentada no gráfico 1, define-se as seguintes porcentagens de cada material presente no solo: pedregulho $0 \%$, areia grossa $19 \%$, areia média $5 \%$, areia fina $10 \%$, silte $38 \%$, argila $28 \%$. Em termos gerais, tem-se $34 \%$ de areia, $38 \%$ de silte e $28 \%$ de argila. Dessa forma, a característica principal desse solo é de um silte, e este é um material que apresenta baixa resistência segundo Almeida (2005). Através dos ensaios de limite consistência, foi determinado os seguintes parâmetros: limite de liquidez $(W L)=33,7$, limite de plasticidade $(W P)=26,8$, encontrando o índice de plasticidade $(I P)=6,9$. 0 que demonstra que o solo em questão é pouco plástico. A partir da Carta de Plasticidade de Pinto (2006), conforme a figura 6, o solo é classificado como ML, o que significa silte de baixa compressibilidade.

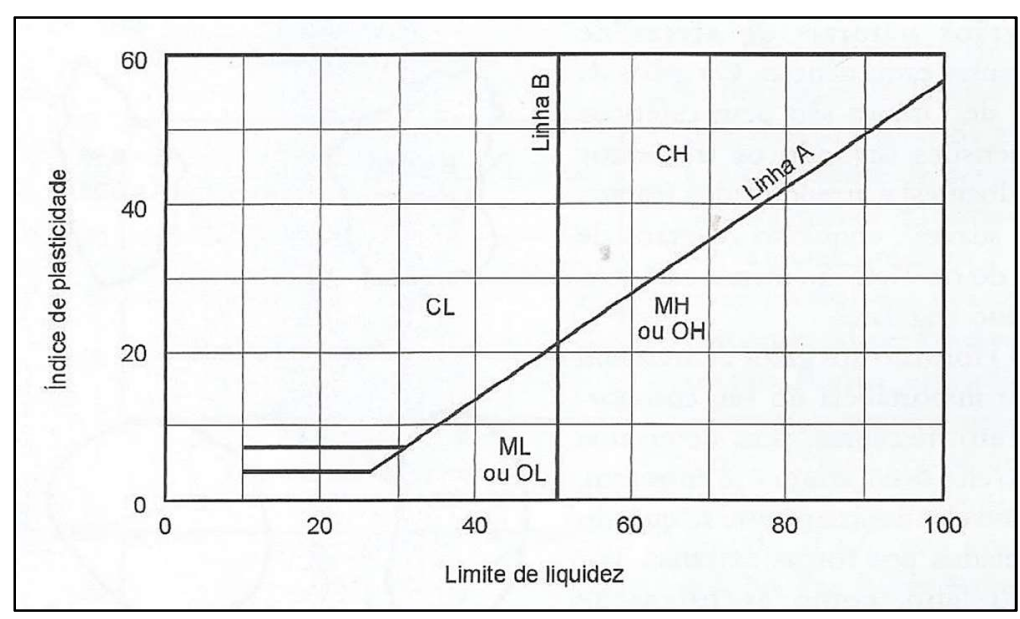

Figura 6: Carta de Plasticidade. Fonte: Pinto (2006). 
Já no que se refere ao ensaio de massa específica, foi encontrado um valor de $2,75 \mathrm{~g} / \mathrm{cm}^{3}$. Para o ensaio de compactação com energia normal, encontrou-se uma massa específica aparente seca ( $\rho$ d) de 1,54 $\mathrm{g} / \mathrm{cm}^{3}$ e uma umidade ótima ( $w_{\text {ót }}$ ) de $22 \%$. A partir disso, foi feito o ensaio de CBR e expansão, e para o referido solo, o CBR verificado foi de $1,12 \%$, e a expansão foi de $3,21 \%$.

Diante dos resultados, percebe-se o porquê de o solo ter sido descartado da pavimentação do seu local de coleta. Solos com CBR inferior a $2 \%$, não servem para nenhuma camada de pavimentação. Entretanto, a partir de uma estabilização, esse solo pode adquirir uma resistência considerável. A estabilização a partir da adição de sílica influenciou na mudança de todas as características do solo. A granulometria passou a ter os seguintes percentuais: areia grossa $19 \%$, areia média $5 \%$, areia fina $9 \%$, silte $40 \%$, e argila $27 \%$, conforme mostra a figura 7.

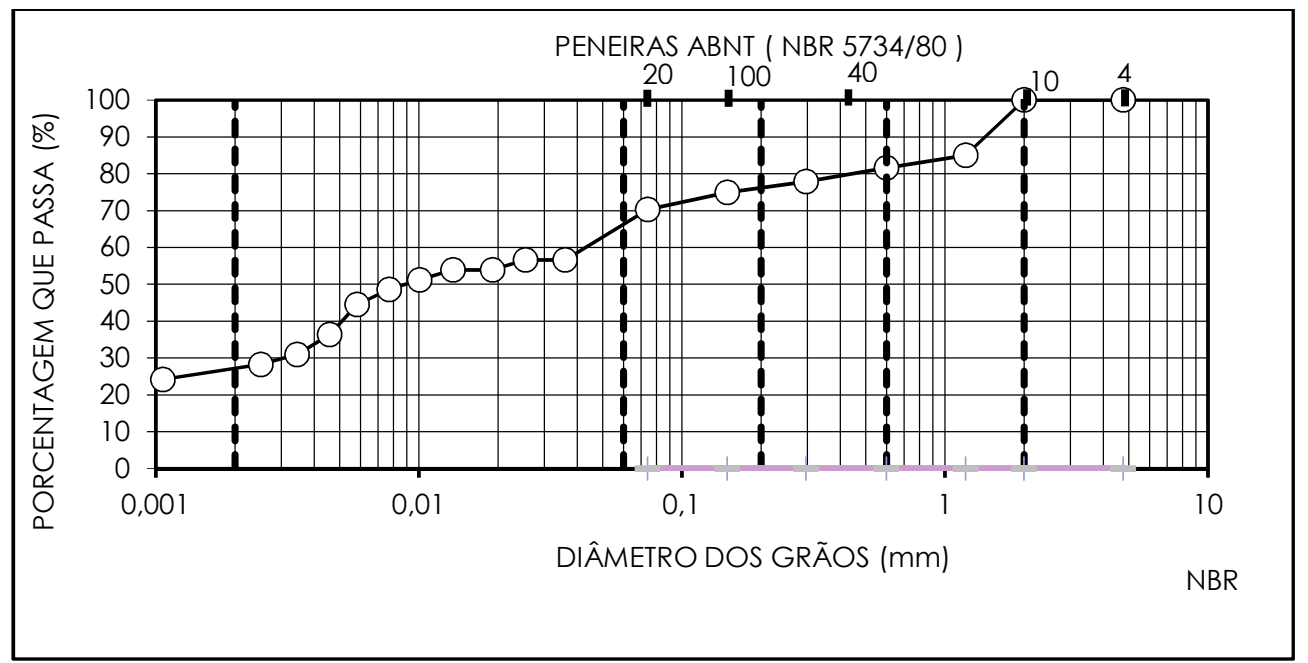

Figura 7: Gráfico de curva de distribuição granulométrica do solo com 15\% de sílica ativa.

Para os limites de consistência, os resultados obtidos foram: $W L=38,3, W P=27,6$ e IP $=10,7$. Algo que tornou o solo com uma plasticidade média, porém não influenciou na caracterização do solo através da Carta de Plasticidade de Pinto (2006), que continuou como silte de baixa compressibilidade. A massa específica da mistura foi definida como $2,70 \mathrm{~g} / \mathrm{cm}^{3}$. A massa específica aparente seca de $1,37 \mathrm{~g} / \mathrm{cm}^{3}$, e a umidade ótima a partir do ensaio de compactação com energia normal, é de $29 \%$. A partir disso, o CBR encontrado foi de 3,59\% e a expansão de 3,73\%.

Percebe-se, então, uma melhora significativa no que se refere à resistência do solo, isso porque ele natural possui um CBR de 1,12\%, o que constitui em mais de três vezes menos que o CBR do solo estabilizado a partir da adição da sílica, que passou a ser 3,59\%. Já para a estabilização do solo a partir da adição de cimento Portland CP-32 II-F, a granulometria encontrada foi de 20\% de areia grossa, $7 \%$ de areia média, 23\% de areia fina, $35 \%$ de silte e $15 \%$ de argila, conforme é visto na figura 8 . Apesar do cimento ser um material fino, é visível que a maior parcela do solo foi de material granular, isso pode ser explicado pela verificação da aglomeração dos grãos com o cimento. 


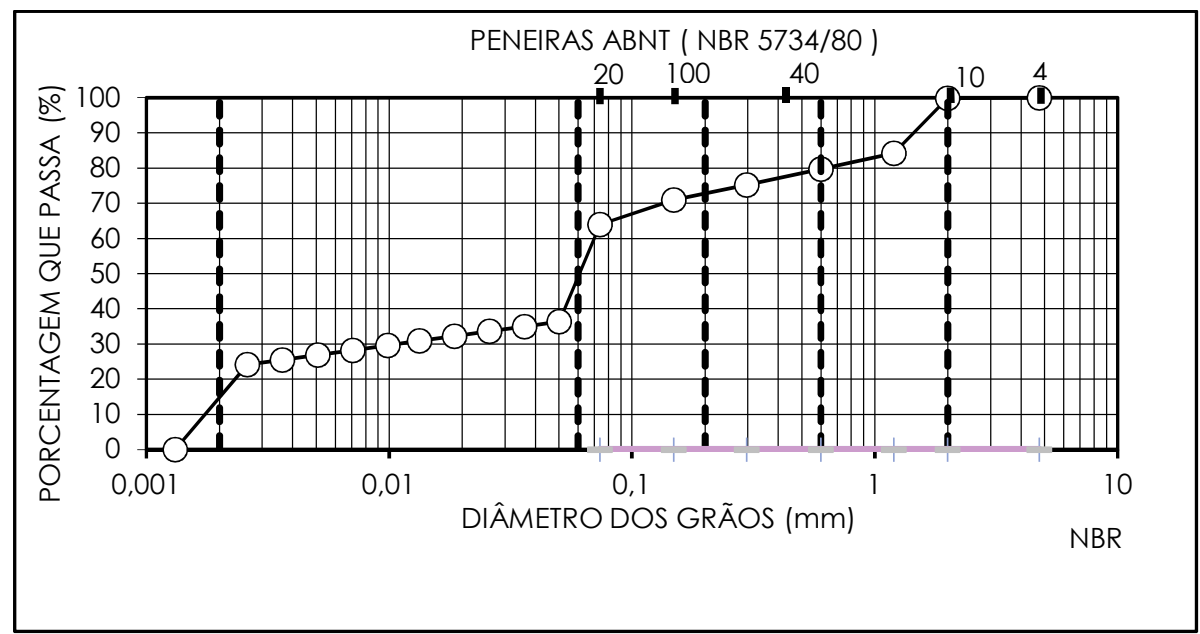

Figura 8: Gráfico de curva de distribuição granulométrica do solo com 15\% de cimento.

Para a mistura solo-cimento, os limites de Atterberg encontrados foram: $W L=34,2, W P=26,5$ e IP $=$ 7,7. Diante disso, percebe-se que o cimento não influenciou muito na plasticidade do solo, que continua sendo considerado pouco plástico. Além de continuar na classificação de silte de baixa compressibilidade, diante dos seus valores de liquidez e plasticidade. Já a massa específica dos sólidos passou a ser $2,89 \mathrm{~g} / \mathrm{cm}^{3}$. A massa específica aparente seca, a partir do ensaio de compactação com energia normal foi de $1,57 \mathrm{~g} / \mathrm{cm}^{3}$, e a umidade ótima foi de $23,4 \%$.

No que diz respeito ao ensaio de CBR e expansão, apesar de ter sido feito, não foi possível realizar as leituras da penetração do material, isso porque ele possui uma consistência muito dura quando compactado, além do cimento misturado à parcela de grãos do solo e imerso em água, transforma-se em argamassa. Dessa forma a leitura foi inconclusiva com números, entretanto entende-se que o material possui uma resistência excelente. Já sua expansão foi de 0,66\%. A título de curiosidade, após o material não ter sido penetrado para o ensaio de CBR, uma amostra foi colocada na prensa hidráulica para verificar sua resistência em Mpa, conforme ilustra a figura 9.

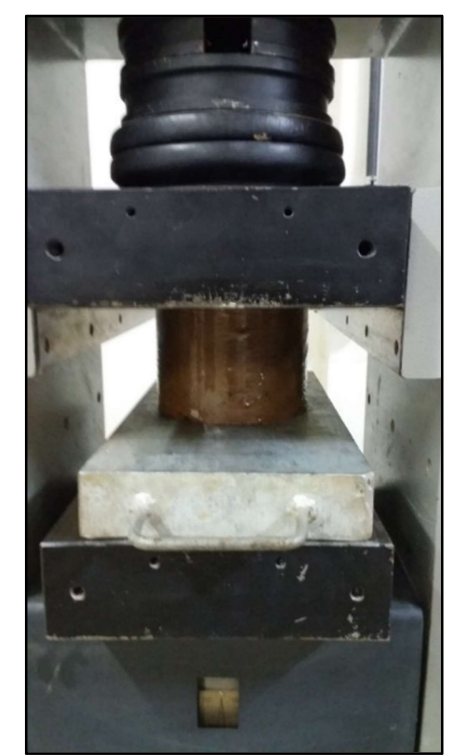

Figura 9: Amostra de solo-cimento em prensa hidráulica.

E foi encontrado uma resistência de 1,55 Mpa ou 28,5 KN. Um valor considerável, por se tratar de um solo. De um modo geral, as características do solo natural e do solo com as misturas de $15 \%$ de sílica ou 
cimento, são apresentados na tabela 1. No que se refere aos limites de liquidez e plasticidade, a adição de 15\% de sílica ao solo promove uma melhora significativa, que diante do índice de plasticidade é visto que o solo passa de pouco plástico para um solo de média plasticidade. Já com a adição de $15 \%$ de cimento, o índice de plasticidade apesar de ter uma melhora, não foi suficiente para que o solo saísse da classificação de pouco plástico.

Tabela 1: Características do solo natural e solo modificado.

\begin{tabular}{|c|c|c|c|}
\hline & Solo natural & Solo + 15\% de sílica & Solo $+15 \%$ de cimento \\
\hline $\mathbf{W L}$ & 33,7 & 38,3 & 34,2 \\
\hline WP & 26,8 & 27,6 & 26,5 \\
\hline IP & 6,9 & 10,7 & 7,7 \\
\hline$\rho s\left(\mathrm{~g} / \mathrm{cm}^{3}\right)$ & 2,75 & 2,7 & 2,89 \\
\hline$\rho d\left(g / \mathrm{cm}^{3}\right)$ & 1,54 & 1,37 & 1,57 \\
\hline Wot (\%) & 22 & 29 & 23,40 \\
\hline CBR (\%) & 1,12 & 3,59 & \\
\hline Expansão (\%) & 3,21 & 3,73 & 0,66 \\
\hline
\end{tabular}

Quanto à massa específica dos sólidos, a adição de $15 \%$ de sílica ativa diminui o valor do solo inicial, e a adição de $15 \%$ de cimento aumenta. Já a massa específica aparente seca, percebe-se que a adição da sílica diminui o valor encontrado no solo natural, enquanto a adição de cimento aumenta uma quantidade pequena. Para a umidade ótima, a adição de $15 \%$ de sílica aumenta consideravelmente esse teor, isso é explicado pelo fato de a sílica solicitar muita água, já a adição de $15 \%$ de cimento promove pouca mudança para essa umidade.

Se comparar os resultados com a adição de sílica ativa, com a pesquisa de Alcântara (2017), que utilizou $5 \%$ e $10 \%$ de cinza de casca de arroz (CCA) como auditivo auxiliar a adição de $8 \%$ de cal, e obteve uma redução do índice de plasticidade, aumento da umidade ótima e diminuição da massa específica aparente seca, percebe-se mesmo acontece com esta referida pesquisa, onde apenas a adição de $15 \%$ de sílica ativa foi capaz de ter resultados tão significativos quanto os verificados pelo autor, com diferença apenas no índice de plasticidade que nesta presente pesquisa houve um aumento.

Já o CBR, que é o ponto mais considerável dessa pesquisa, por se tratar da resistência do solo para ser usado em camadas de pavimentação, percebe-se que o solo possui uma resistência muito baixa, apenas $1,12 \%$ de CBR, e que, portanto, não pode ser usado em nenhuma camada de pavimentação. Isso porque, considerando as camadas de solo na pavimentação como base, sub-base, reforço do subleito e subleito, nenhuma delas deve possuir um $C B R \leq 2 \%$. Segundo o DNIT (2006), a base deve apresentar um CBR $\geq 80 \%$, a sub-base um $C B R \geq 20 \%$, o reforço do subleito um CBR maior que o do subleito, e o subleito um CBR $\geq 2 \%$.

Através da estabilização química com a adição de sílica, o CBR do solo assume um valor de 3,59\%, podendo ser utilizado nas camadas mais 'pobres' da pavimentação, como o subleito, e talvez o reforço do subleito. Entretanto, mesmo não sendo utilizado em camadas mais nobres, essa estabilização promove uma melhora considerável, visto que o solo era muito pobre e ao ser estabilizado melhorou sua resistência em mais de três vezes. Provavelmente se o solo fosse de melhor qualidade, a adição de sílica melhoraria bastante a sua resistência e poderia ser utilizado em camadas mais nobres. A diferença entre as amostras pode ser 
percebida inclusive pela visível penetração e consistência dos corpos de prova do solo e do solo com 15\% de sílica, conforme as figuras 10 e 11, respectivamente.

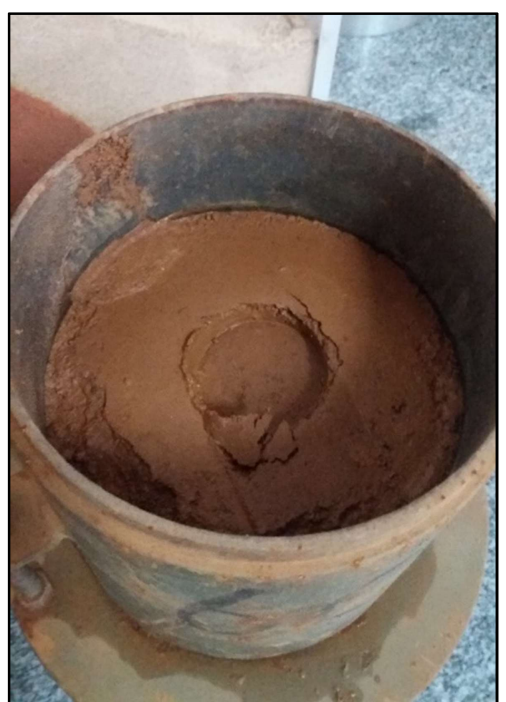

Figura 10: Estado da amostra de solo natural após os ensaios de CBR e expansão.

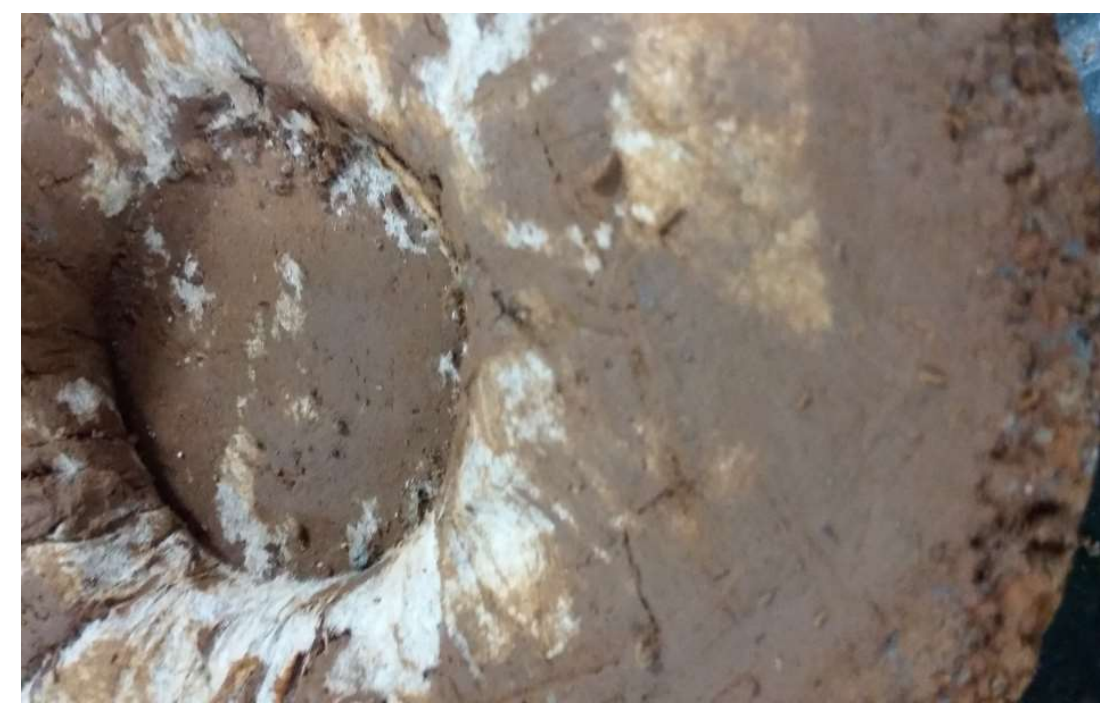

Figura 11: Estado do solo-sílica após os ensaios de CBR e expansão.

Percebe-se que o solo natural possui uma maior perfuração, além da sua consistência se apresentar mais mole e quebradiça com a aplicação de esforços para perfurar, em comparação com o solo com $15 \%$ de sílica. Se comparado aos valores encontrados nas pesquisas de Klamt (2012) e Fernandes (2014), percebemos que a adição de sílica ativa, assim como a adição de cal juntamente com cinza da casca de arroz (CCA), que é um material utilizado atualmente para produção de sílica, promoveu melhorias tão significativas quanto seus trabalhos. Vale ressaltar que essa comparação não é feita através de porcentagens visto que as amostras dos autores foram submetidas ao ensaio de cisalhamento direto, para encontrar a resistência, enquanto as amostras da presente pesquisa foram submetidas ao ensaio de CBR.

Apesar dos materiais dos referidos autores terem alcançado maiores resistências, em decorrência da utilização de um solo melhor, não desqualifica os encontrados nesta pesquisa, isso porque mesmo com um solo de uma qualidade muito baixa, a sílica promoveu uma melhoria de mais de três vezes na resistência.

No que se refere à expansão, a sílica contribuiu para que aumentasse a expansão do solo, que passou de 3,21\% para 3,73\%, algo que é considerado um ponto negativo. Já a adição de $15 \%$ de cimento ao solo, no que se refere ao $C B R$, é verificado uma melhora muito significativa, isso porque o cimento promoveu uma resistência tão alta que ele não teve uma perfuração quantificada, o que demonstra que o CBR do material é muito alto. Isso é verificado, também, conforme sua visível penetração e consistência, através da figura 12.

Percebe-se que a perfuração na amostra foi muito pequena e sua consistência é rija. Comparando com os outros dois tipos de amostra, essa é a que teve as melhores características de resistência. Considerando que por não haver uma leitura do CBR diante da sua dureza, esse solo estabilizado com cimento pode ser usado em todas as camadas de pavimentação. Entretanto este é um caso que deve ser analisado, considerando que o cimento é um material que pode encarecer a estabilização e, portanto, deve ser visto o caso a que a estabilização está submetida. Já para o ensaio de expansão, o uso de cimento ao solo 
contribuiu para uma demasiada diminuição, contribuindo, portanto, para uma melhoria dessa característica do solo, sendo que a expansão do solo era de $3,21 \%$ e passou a ser $0,66 \%$ com a adição do cimento.

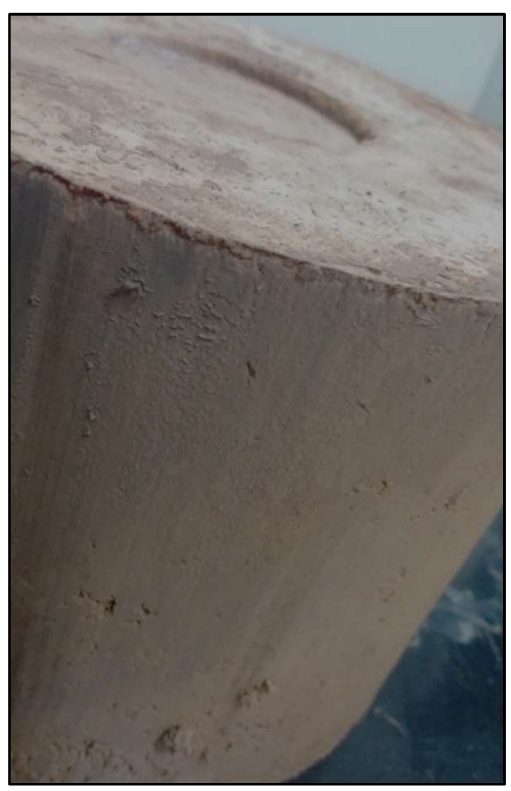

Figura 3: Estado do solo-cimento após os ensaios de CBR e expansão.

\section{CONCLUSÕES}

As análises feitas nesta referida pesquisa, levaram a percepção que o uso de sílica para estabilização de solos é uma prática com bons resultados, onde para o solo utilizado houve uma melhora de mais de três vezes em sua resistência. Apesar desse ganho de três vezes a mais de resistência no referido solo, devido ao mesmo se tratar de um solo de baixíssima resistência, mesmo após a estabilização não poderia ser utilizado em camadas nobres de pavimentação, somente em camadas como o subleito e talvez o reforço do subleito. Entretanto, para solos com baixa qualidade, mas com uma resistência inicial mais considerável, através da adição de sílica ativa pode gerar ganhos suficientes para que deixe de ser utilizado apenas em subleito e passe a ser utilizado em camadas mais nobres, a depender da resistência inicial e final.

Dessa forma, entende-se que não há a necessidade de utilizar a sílica somente como um aditivo auxiliar à cal hidratada, pois mesmo sozinha, ela contribui para estabilizar o solo. E além da resistência, ela auxilia no aumento do índice de plasticidade do solo, tornando-o de pouco plástico para uma média plasticidade, auxilia no aumento da umidade ótima, diminuição da massa específica dos sólidos e diminuição da massa específica aparente seca. Entretanto há um ponto negativo, onde a sílica aumenta a expansão do solo.

No que se refere ao uso do cimento, ele promove uma melhora demasiada à resistência do solo, muito superior ao uso da sílica. Entretanto, diferente da sílica, ele aumenta a massa específica dos sólidos e a massa específica seca. Também contribui para aumentar o índice de plasticidade, e a umidade ótima, porém em pouca quantidade. Já no quesito de expansão, o cimento promove uma melhora extremamente significativa, isso porque diminuiu em mais de quatro vezes a expansão do solo natural.

Apesar de o uso do cimento promover uma melhoria maior no quesito resistência e expansão, o uso da sílica também auxilia na estabilização. A decisão do melhor material a ser utilizado vai depender das 
necessidades da obra, como por exemplo a disposição dos materiais em torno da obra, ou até mesmo a quantidade de aumento do CBR necessária, aliada à um solo que o pouco aumento da expansão provocado pela sílica não influencie no seu uso, ou a necessária diminuição da expansão, que é ocorrida com a adição do cimento.

\section{REFERÊNCIAS}

ALCÂNTARA, M. A. M.. Efeito da cinza de casca de arroz na plasticidade e compactação de uma mistura solo-cal. Revista Matéria, Rio de Janeiro, v.22, n.3, 2017.

ALMEIDA, G. C. P.. Caracterização Física e Classificação dos Solos. Juiz de Fora: UFJF, 2005.

DNIT. Departamento Nacional de Infraestrutura de Transportes. Manual de Pavimentação. 3 ed. Rio de Janeiro: DNIT, 2006.

FERNANDES, W. D.. Verificação da resistência ao cisalhamento e estabilidade de taludes de um solo natural e melhorado com cimento, cal e cinza da casca de arroz. Alegrete: UNIPAMPA, 2017.
KLAMT, R. A.. Utilização de cinza da casca de arroz no melhoramento das propriedades mecânicas de um solo não laterítico da formação Botucatu. In: CONGRESSO BRASILEIRO DE MECÂNICA DOS SOLOS E ENGENHARIA GEOTÉCNICA, 16. Anais. Belo Horizonte: 2016.

PINTO, C. S.. Curso Básico de Mecânica dos Solos. 3 ed. São Paulo: Oficina de Textos, 2006.

SARTORI, G.. Estudo de estabilização de solos para fins de pavimentação da região de Campo Mourão. Campo Mourão: UTFPR, 2015.

A CBPC - Companhia Brasileira de Produção Científica (CNPJ: 11.221.422/0001-03) detém os direitos materiais desta publicação. Os direitos referem-se à publicação do trabalho em qualquer parte do mundo, incluindo os direitos às renovações, expansões e disseminações da contribuição, bem como outros direitos subsidiários. Todos os trabalhos publicados eletronicamente poderão posteriormente ser publicados em coletâneas impressas sob coordenação da Sustenere Publishing, da Companhia Brasileira de Produção Científica e seus parceiros autorizados. Os (as) autores (as) preservam os direitos autorais, mas não têm permissão para a publicação da contribuição em outro meio, impresso ou digital, em português ou em tradução. 